\title{
The Impact of COVID-19 on Hip Fracture Management in a Tertiary Referral Hospital; Pearls and Pitfalls.
}

\section{Curran MG ( $\nabla$ mcurran13@hotmail.com )}

University of Limerick https://orcid.org/0000-0002-7200-3118

\section{Hickey P}

University Hospital Limerick

\section{Reddin C}

University Hospital Limerick

\section{Murphy R}

University Hospital Limerick https://orcid.org/0000-0001-5446-4175

\section{Mohd Asri NA}

University Hospital Limerick

\section{Lenehan, $B$}

University Hospital Limerick

\section{Condon $\mathrm{F}$}

University Hospital Limerick

\section{Ryan J}

University Hospital Limerick

\section{Research Article}

Keywords: COVID-19, Hip Fractures, Orthogeriatrics

Posted Date: November 25th, 2020

DOl: https://doi.org/10.21203/rs.3.rs-115034/v1

License: (a) This work is licensed under a Creative Commons Attribution 4.0 International License. Read Full License 


\section{Abstract}

Background

COVID-19 has caused significant challenges in the provision of safe and effective healthcare globally. Safeguarding the management of frail older adults is imperative in hip fracture care moving forward.

\section{Aims}

This study aimed to compare clinical outcomes of hip fracture care during the COVID-19 pandemic with the same timeframe in 2019, following significant reconfigurations in hip fracture management pathways during the pandemic.

Methods

We conducted a retrospective study comparing all patients treated for a hip fracture between two timeframes; March $1^{\text {st }} 2020$ - May $1^{\text {st }} 2020$ and March $1^{\text {st }} 2019$ - May $1^{\text {st }} 2019$. Data was collected using the Irish Hip Fracture Database and the UHL electronic patient administration system.

Results

118 patients were included in the study; 60 patients in the COVID-19 cohort and 58 patients in the control cohort. Demographic characteristics were comparable between groups. Improvements in adherence to Irish Hip Fracture Standards were noted during the COVID-19 cohort, however they were not significant. Three patients tested positive for COVID-19 during the timeframe of interest. Their length of stay (LOS) was noticeably longer than the median LOS of both groups. A significant decrease in femoral nerve blocks was noted during the COVID-19 cohort $(p=<0.001)$. There was a trend towards higher inpatient mortality, 30 day mortality rates and 30 day readmission in the COVID-19 cohort which was not statistically significant.

Conclusions

Our study demonstrates continued adherence to the Irish Hip Fracture Standards at our institution and suggests the necessary alterations in hip fracture management did not negatively impact patient outcomes during the COVID-19 pandemic.

\section{Background}

COVID-19 has caused unprecedented challenges the world over, leading to both direct and indirect consequences on healthcare provision and those who access it (1). Ireland, like many other countries, underwent an initial nationwide lockdown on March $28^{\text {th }}$, in a national effort to curtail the spread of the virus. Our institution reconfigured its' operating systems to adapt and introduce innovative strategies to maintain quality care. Patients who experience hip fractures are frequently frail older adults with multi- 
morbidity (2). This increases both their risk of contracting COVID-19 and subsequently increases their risk of mortality as a result COVID-19 (3), therefore safeguarding their management was a priority.

University Hospital Limerick (UHL) treats approximately 300 people with hip fractures annually (4). Hip fractures are one of the most common serious injuries affecting older adults and are associated with a one year mortality rate of up to $30 \%$ (5). Our institution has seen significant improvements in hip fracture management over the last decade, particularly since the introduction of a formal Orthogeriatric Service, and we have witnessed sustained improvements in our adherence to Irish Hip Fracture Standards of Care (IHFS) $(6,7)$. Building on these earlier improvements we wished to investigate the impact of COVID-19 on clinical outcomes, and compliance with IHFS, and to evaluate the impact of the reconfiguration of our operating systems. Prior to an anticipated second wave it is important to have evaluated the effect of our departmental response on clinical outcomes following hip fracture in our institution.

\section{Methods}

We conducted a retrospective cohort study comparing all patients who presented with a hip fracture between two specific time frames; March $1^{\text {st }} 2020$ - May $1^{\text {st }} 2020$ (the COVID-19 cohort) and March $1^{\text {st }}$ 2019 - May $1^{\text {st }} 2019$ (the control cohort). The same time period from each year was selected to limit seasonal confounding. All patients who presented to UHL with a hip fracture during both timeframes were included. This selected time period reflects the initial alteration in established hip fracture referral pathways, which took place just two days after the first confirmed case of COVID-19 in Ireland. These initial alterations continued for nine weeks until May $1^{\text {st }} 2020$ when key staff who had been redeployed during the pandemic response were reinstated.

Data was extracted from the electronic patient administration system at UHL and from the Irish Hip Fracture Database (IHFD), which is prospectively maintained with data entry by a dedicated Orthopaedic Clinical Nurse Specialist. Variables of interest included patient demographics, fracture type, operation and anaesthesia used, acute length of stay, discharge destination and source of admission. When evaluating discharge destination, we included only patients who survived to discharge who were previously dwelling at home. Thirty day mortality and readmission rates were compared between groups. We explored changes in the departmental structure, referral pathways, discharge disposition, post-acute care followup, and adherence to the IHFS. Statistical analysis was undertaken using SPSS version 26. MannWhitney U, Chi Square Test and Fisher's Exact Test were used for non-parametric variables. Statistical significance was considered at $\mathrm{P}<0.05$.

\section{Results}

Patient Demographics

118 patients were treated at our institution during the two time frames of interest. There were similar numbers of patients during each timeframe (COVID-19 cohort, $N=60$, and the control cohort, $N=58$ ). The 
median age in the COVID-19 cohort was 82 years $(\min =37, \max =95, I Q R=14.5)$, while the median age for the control cohort was 75 years $(\min =31, \max =93, I Q R=18.25)$. The difference in medians between groups was not significant $(p=0.213)$. Both cohorts had a higher proportion of female patients; 37 females $(61.7 \%)$ in the COVID-19 cohort and 40 females (69\%) in the control group. Fourteen patients (23.3\%) were admitted from nursing homes in the COVID-19 cohort compared to five patients (8.6\%) in the control group $(p=0.052)$. Clinical Activity Scores (CAS) were also collected on admission with a mean score of 5.05 +/- 3.52 SD in the COVID-19 cohort and 5.83 +/- 3.23 SD in the control group.

Inpatient care

We noted trends towards increased adherence in each of the IHFS, with a proportional improvement in each standard in the COVID-19 time period, though this was not a statistically significant difference (Table 1).

Table 1: Adherence to the Irish Hip Fracture Standards (IHFS)

Details of the type of fractures sustained, operations performed, American Society of Anaesthesiologists Classification (ASA) grades and anaesthesia used for both groups can be found in Table 2. There was a statistically significant reduction in femoral nerve blocks to $65 \%$ in the COVID-19 cohort compared to $88 \%$ in the control group $(p=<0.001)$

Table 2: Surgical demographics for both cohorts

The median length of stay (LOS) was 7.5 days ( $\min =2$, $\max =66$, IQR=11) in the COVID-19 cohort compared to 10.0 days $(\min =1$, $\max =66, I Q R=18)$ in the control group $(p=0.345)$.

\section{Discharge destination}

A significant increase in new admissions to nursing homes occurred during the COVID-19 period ( $p=$ 0.04). Concurrent decreases were also noted in the proportion of patients discharged directly home, however this was not statistically significant. Other details pertaining to discharge destination in patients admitted directly from the community are included in Table 3.

Table 3: Discharge destination for patients admitted from the community

\section{Readmission rates and Mortality rates}

There was a trend towards an increased 30 day readmission rate for the COVID-19 cohort at $6.7 \%(n=4)$ compared to $1.7 \%$ in the control cohort $(n=1)$, though this was not statistically significant $(p=0.36)$. Reason for readmission in the COVID-19 cohort included recurrent falls $(n=2)$, an upper respiratory tract infection $(n=1)$ and persistent pain around the prothesis post-operatively $(n=1)$. The sole readmission in the control group was for a query deep vein thrombosis. 
Inpatient mortality for the COVID-19 cohort was 8.3\% $(n=5)$ compared to $5.2 \%(n=3)$ in the control group. Subsequent 30 day mortality rate was $10 \%(n=6)$ in the COVID-19 cohort compared to $6.9 \%(n=4)$ in the control group.

\section{COVID-19 screening}

In the COVID-19 cohort 48.33\% ( $n=29)$ of patients had a swab for COVID-19. As per clinical guidance at the time any low risk patients were not swabbed. Three of these patients tested positive for COVID-19 $(5 \%)$. Two of the these patients were admitted from nursing homes. One of the patients was deemed unfit for surgery and died as an inpatient after four days. The other two COVID-19 positive patients underwent surgical repair of their fractures, their LOS was 26 and 31 days respectively.

Telemedicine

Telemedicine clinics became the standard of care for routine 30 day post-operative fracture clinic assessments. There was an improvement in patient follow-up such that $76 \%$ of patients in the COVID-19 cohort had complete 30 day assessments versus $36 \%$ in the control group. In the virtual clinic cohort of patients there was a high rate of direct discharge (64\%) back to GP care following virtual review.

\section{Discussion}

This study of 118 participants evaluating clinical outcomes following reconfiguration of hip fracture care demonstrated no significant difference in adherence to IHFS between cohorts (Table 1). Concerns that changes in practice, and redeployment of some staff, might have contributed to worse adherence were not borne out. In fact, each of six individual standards demonstrated some improvement over the corresponding time period, though these changes were not statistically significant. These finding highlight the commitment of both the geriatric and orthopaedic department to delivering ongoing high quality hip fracture care despite the disruptions in the established 'fast track' pathway for hip fracture management in the hospital. Traditionally, hip fracture patients are stabilised in the Emergency Department (ED), assessed by a senior ED decision maker or an Orthopaedic registrar and subsequently admitted direct from ED to an orthopaedic specialist ward within four hours. While the emergence of a COVID-19 response pathway had redirected hip fracture patients away from the ED after initial X-ray to a separate initial assessment unit, it was reassuring to note that this did not negatively affect IHFS 1.

Alterations in practice may have resulted in an unintended outcome of statistically significant reduction in the proportion of patients who had undergone femoral nerve blocks; $65 \%$ in the COVID-19 cohort compared to $88 \%$ in the control group. Given the well-established links with superior analgesia, reduced incidence of pneumonia and earlier mobilisation following regional anaesthesia (8) this decline in practice was likely detrimental to patient care. A trend towards a reduced median LOS in the COVID-19 cohort was also noted ( 7.5 days vs 10 days). While this was in line with guidance at the time to expedite 
discharges to maximise bed capacity and prevent nosocomial transmission of COVID-19, we have observed a number of potential unintended consequences which may be linked to this reduction in LOS.

More patients were transferred to Model 2 hospitals, for ongoing care, instead of direct discharges either to home or dedicated rehabilitation facilities. We noted that there was a trend towards higher 30 day readmission rates in the COVID-19 cohort, and this may also reflect the fact that there were less admissions to dedicated rehabilitation services. Increases in both the inpatient mortality rate and 30 day mortality rates were also noted in the COVID-19 cohort, however these were not statistically significant. Of course, premorbid functional status and pre-existing comorbidities are also an important consideration when assessing the aforementioned trends. Despite notable increases in nursing home admissions mean Clinical Activity Scores (CAS) were comparable between both groups suggesting no significant difference in functional status. Similarly, multivariate analysis comparing mortality and readmission rates with both CAS and ASA grades proved inconclusive.

Internationally it has been noted that there have been increased peri-operative complications and increased mortality rates in COVID-19 positive patients with hip fractures (9-11). We have provided a narrative summary of three patients who had hip fractures who were COVID-19 positive, and while this is a small case series, it demonstrates consistent findings with a definite mortality risk, and prolonged LOS.

We noted a trend towards more patients being admitted directly from nursing homes with fourteen patients (23.3\%) of the COVID-19 cohort being admitted from nursing homes compared to just five patients $(8.6 \%)$ in the control group. This was not a significant difference $(p=.052)$ but signifies a notable alteration in demographics between both cohorts and may explain the 7 year median difference in age between both groups. This may be another example of the inadvertent consequences of COVID-19, with the potential for less rigorous supervision of patients due to social distancing recommendations or COVID-19 related staff shortages $(12,13)$. Our study highlights the need for a high index of suspicion for COVID-19 when patients are admitted from a nursing home, particularly as COVID-19 can present atypically in this patient population with delirium and falls $(14,15)$. The comparative increase in the proportion of patients being admitted from a nursing home rather than from the community in the COVID19 cohort could also reflect the effect of 'cocooning' on older adults. This is something which needs to be borne out with more long term epidemiological data, as restrictions on peoples movements could lead to long term deconditioning and future risk of fragility fractures (16).

Rapid advances in virtual fracture clinics during the COVID-19 pandemic have provided a new method of interacting with patients. The initiation of telemedicine clinics reduced the risk of transmission of the virus, while also ensuring adequate provision of outpatient care. Virtual clinics have grown in popularity during the COVID-19 pandemic (17) and are largely touted as an efficient means of delivering care to fracture clinic patients and to older adults $(18,19)$. Data from patient cohort demonstrates satisfactory outcomes from the clinic with $64 \%$ of the cohort being discharged without the need for further follow-up. 'Did not attend' rates also decreased during the pandemic. 
Our study has some limitations. It is a single centre, retrospective study, and as such it may be underpowered to detect changes in outcomes in the COVID-19 period. Large amounts of our data was extracted from the Hip Fracture Database. Although this data is prospectively collected, omissions are possible. However, this is mitigated in our institution by employing a trained Orthopaedic Specialist Nurse as data coordinator to ensure consistent high quality of data collection. Having the same staff member entering the data from both time sets also avoids misclassification bias. Strengths of the study include the homogeneity of the populations in question.

\section{Conclusion}

In conclusion our study has demonstrated continued adherence with IHFS during the COVID-19 pandemic. While we noted encouraging trends towards reduced LOS, we also noted a trend towards increased re-admission and 30 day mortality rates. Overall, our findings are a testament to the healthcare services' ability to react to change and to respond proactively in the face of the challenges we have highlighted.

\section{Declarations}

\section{Ethical approval}

Ethical approval was granted by the HSE Mid-Western Area Research Ethics Committee prior to commencing the study.

\section{Competing interests:}

The authors declare no competing interests.

\section{Sources of funding}

MC was supported by a Medical Education Liaison Group (MELG) Student Research Bursary, 2020. The funding source had no role in the design and conduct of the study; the collection, management, analysis, and interpretation of the data; the preparation, review, or approval of the manuscript; or the decision to submit the manuscript for publication.

\section{Disclosures}

All authors declare no competing interests.

\section{References}


1. Figueroa JD, Brennan PM, Theodoratou E, Poon MTC, Purshouse K, Din FVN, et al. Distinguishing between direct and indirect consequences of covid-19. BMJ. 2020 15;369:m2377.

2. Folbert EC, Hegeman JH, Vermeer M, Regtuijt EM, van der Velde D, ten Duis HJ, et al. Improved 1-year mortality in elderly patients with a hip fracture following integrated orthogeriatric treatment. Osteoporos Int. 2017 Jan;28(1):269-77.

3. Docherty AB, Harrison EM, Green CA, Hardwick HE, Pius R, Norman L, et al. Features of 16,749 hospitalised UK patients with COVID-19 using the ISARIC WHO Clinical Characterisation Protocol [Internet]. Infectious Diseases (except HIV/AIDS); 2020 Apr [cited 2020 Jul 23]. Available from: http://medrxiv.org/lookup/doi/10.1101/2020.04.23.20076042

4. National Office of Clinical Audit. Irish Hip Fracture Database National Report 2018 [Internet]. 2019. Available from: https://www.noca.ie/documents/ihfd-national-report-2018

5. Downey C, Kelly M, Quinlan JF. Changing trends in the mortality rate at 1-year post hip fracture - a systematic review. World J Orthop. 2019 Mar 18;10(3):166-75.

6. National Office of Clinical Audit. Irish Hip Fracture Database National Report 2018 [Internet]. 2019. Available from: https://www.noca.ie/documents/ihfd-national-report-2018

7. Henderson CY, Shanahan E, Butler A, Lenehan B, O'Connor M, Lyons D, et al. Dedicated orthogeriatric service reduces hip fracture mortality. Ir J Med Sci. 2017 Feb;186(1):179-84.

8. Guay J, Parker MJ, Griffiths R, Kopp S. Peripheral nerve blocks for hip fractures. Cochrane Anaesthesia Group, editor. Cochrane Database of Systematic Reviews [Internet]. 2017 May 11 [cited 2020 Aug 3]; Available from: http://doi.wiley.com/10.1002/14651858.CD001159.pub2

9. Hall AJ, Clement ND, Farrow L, IMPACT-Scot Study Group, MacLullich AMJ, Dall GF, et al. IMPACTScot report on COVID-19 and hip fractures: a multicentre study assessing mortality, predictors of early SARS-CoV-2 infection, and the effects of social lockdown on epidemiology. The Bone \& Joint Journal. 2020 Jul 7;1-10.

10. Kayani B, Onochie E, Patil V, Begum F, Cuthbert R, Ferguson D, et al. The effects of COVID-19 on perioperative morbidity and mortality in patients with hip fractures: a multicentre cohort study. The Bone \& Joint Journal. 2020 Jul 7;1-10.

11. Muñoz Vives JM, Jornet-Gibert M, Cámara-Cabrera J, Esteban PL, Brunet L, Delgado-Flores $L$, et al. Mortality Rates of Patients with Proximal Femoral Fracture in a Worldwide Pandemic: Preliminary Results of the Spanish HIP-COVID Observational Study*. Journal of Bone and Joint Surgery [Internet]. 2020 May 6 [cited 2020 Jul 27];Publish Ahead of Print. Available from: https://journals.Iww.com/10.2106/JBJS.20.00686

12. Grabowski DC, Mor V. Nursing Home Care in Crisis in the Wake of COVID-19. JAMA. 2020 Jul 7;324(1):23.

13. Kennelly SP, Dyer AH, Martin R, Kennelly SM, Martin A, O'Neill D, et al. Asymptomatic carriage rates and case-fatality of SARS-CoV-2 infection in residents and staff in Irish nursing homes [Internet]. Geriatric Medicine; 2020 Jun [cited 2020 Jul 31]. Available from: http://medrxiv.org/lookup/doi/10.1101/2020.06.11.20128199 
14. O'Hanlon S, Inouye SK. Delirium: a missing piece in the COVID-19 pandemic puzzle. Age and Ageing. 2020 Jul 1;49(4):497-8.

15. Norman RE, Stall NM, Sinha SK. Typically Atypical: COVID -19 Presenting as a Fall in an Older Adult. J Am Geriatr Soc [Internet]. 2020 Jul [cited 2020 Jul 31];68(7). Available from: https://onlinelibrary.wiley.com/doi/abs/10.1111/jgs.16526

16. De Biase S, Cook L, Skelton DA, Witham M, ten Hove R. The COVID-19 rehabilitation pandemic1. Age Ageing [Internet]. 2020 May 29 [cited 2020 Oct 18]; Available from:

https://www.ncbi.nlm.nih.gov/pmc/articles/PMC7314277/

17. Murphy RP, Dennehy KA, Costello MM, Murphy EP, Judge CS, O’Donnell MJ, et al. Virtual geriatric clinics and the COVID-19 catalyst: a rapid review. Age and Ageing. 2020 Aug 20;afaa191.

18. Murphy RP, Dennehy KA, Costello MM, Murphy EP, Judge CS, O’Donnell MJ, et al. Virtual geriatric clinics and the COVID-19 catalyst: a rapid review. Age and Ageing. 2020 Aug 20;afaa191.

19. Murphy EP, Fenelon C, Murphy RP, O'Sullivan MD, Pomeroy E, Sheehan E, et al. Are Virtual Fracture Clinics During the COVID-19 Pandemic a Potential Alternative for Delivering Fracture Care? A Systematic Review. Clin Orthop Relat Res. 2020 Jun 26;

20. den Ouden M, Bleijlevens MHC, Meijers JMM, Zwakhalen SMG, Braun SM, Tan FES, et al. Daily (In)Activities of Nursing Home Residents in Their Wards: An Observation Study. Journal of the American Medical Directors Association. 2015 Nov;16(11):963-8.

\section{Tables}

\section{Standard Standard}

no.

\begin{tabular}{|c|c|c|c|c|}
\hline & & $(N=60)$ & $(N=58)$ & \\
\hline IHFS 1 & $\begin{array}{l}\text { Admission to acute orthopaedic ward within } 4 \\
\text { hours or brought directly to theatre from the } \\
\text { emergency department }\end{array}$ & $\begin{array}{l}34 \\
(56.7 \%)\end{array}$ & $\begin{array}{l}26 \\
(44.8 \%)\end{array}$ & 0.27 \\
\hline IHFS 2 & $\begin{array}{l}\text { Surgery within } 48 \text { hours of admission during } \\
\text { normal working hours (Monday to Sunday, 8:00- } \\
17: 59 \text { ) }\end{array}$ & $\begin{array}{l}36 \\
(60 \%)\end{array}$ & $\begin{array}{l}29 \\
(50 \%)\end{array}$ & 0.37 \\
\hline IHFS 3 & Minimise risk of developing pressure ulcers & $1(1.7 \%)$ & $2(3.4 \%)$ & 0.98 \\
\hline IHFS 4 & $\begin{array}{l}\text { Orthogeriatric review during their initial } \\
\text { admission }\end{array}$ & $\begin{array}{l}48 \\
(80 \%)\end{array}$ & $\begin{array}{l}43 \\
(74.1 \%)\end{array}$ & 0.59 \\
\hline IHFS 5 & Comprehensive bone health assessment & $\begin{array}{l}58 \\
(96.7 \%)\end{array}$ & $\begin{array}{l}56 \\
(96.6 \%)\end{array}$ & 1.00 \\
\hline IHFS 6 & Specialist falls assessment & $\begin{array}{l}57 \\
(95 \%)\end{array}$ & $\begin{array}{l}44 \\
(75.9 \%)\end{array}$ & 0.07 \\
\hline
\end{tabular}

Table 1: Adherence to the Irish Hip Fracture Standards (IHFS)

COVID- Control P 19 group value $(N=60) \quad(N=58)$ Ameican Medical Directors Association. 2015 Nov, $16(11): 963-8$. 


\section{Table 2: Surgical demographics for both cohorts}




\section{Fracture type}

Intracapsular displaced

Intracapsular un-displaced

Intertrochanteric

Subtrochanteric

Periprosthetic

\section{Operation}

Cemented Hemiarthroplasty

Uncemented hemiarthroplasty

Short IM nail

Long IM nail

DHS

Cemented THA

Other

Non-operative management

\section{Pre-operative Nerve Block}

Yes

No

\section{Anaesthesia}

Spinal anaesthesia (SA)

SA + nerve block

General anaesthesia

\section{ASA grade}

I: Healthy

II: Mild/Moderate systemic disease

III: Severe systemic disease limits activity

IV: Severe incapacitating disease. Life threatening.

V: Moribund

VI: Brain dead

Not documented

\begin{tabular}{|ccc|}
\hline $28(46.7 \%)$ & $29(50 \%)$ & 0.35 \\
\hline $2(3.3 \%)$ & $11(19 \%)$ & $<0.01$ \\
\hline $21(35 \%)$ & $15(25.9 \%)$ & 0.08 \\
\hline $6(10 \%)$ & $2(3.4 \%)$ & 0.16 \\
\hline $3(5 \%)$ & $1(1.7 \%)$ & 0.62 \\
\hline
\end{tabular}

\begin{tabular}{ccc}
\hline $23(38.3 \%)$ & $25(43.1 \%)$ & 0.71 \\
\hline $2(3.3 \%)$ & $7(12.1 \%)$ & 0.90 \\
$19(31.7 \%)$ & $12(20.7 \%)$ & 0.15 \\
$5(8.3 \%)$ & $4(6.9 \%)$ & 1.00 \\
$3(5 \%)$ & $3(5.2 \%)$ & 0.72 \\
$1(1.7 \%)$ & $1(1.7 \%)$ & 0.62 \\
\hline $3(5 \%)$ & $2(3.4 \%)$ & 0.12 \\
$4(6.7 \%)$ & $4(6.9 \%)$ & 0.44
\end{tabular}

$\begin{array}{ccc}39(65 \%) & 51(88 \%) & <0.001 \\ 21(35 \%) & 7(12 \%) & <0.001\end{array}$

\begin{tabular}{|ccc|}
\hline $\mathbf{N}=\mathbf{5 6})$ & $\mathbf{( N = 5 4 )}$ & \\
\hline $53(94.6 \%)$ & $46(85.3 \%)$ & 0.13 \\
\hline $0(0 \%)$ & $7(13 \%)$ & 0.03 \\
\hline $3(5.4 \%)$ & $1(1.7 \%)$ & 0.62 \\
\hline $\mathbf{N = 5 6 )}$ & $(\mathbf{N = 5 4 )}$ & \\
\hline $1(1.8 \%)$ & $3(5.6 \%)$ & 0.360 \\
\hline $30(53.6 \%)$ & $23(42.6 \%)$ & 0.145 \\
\hline $23(41.1 \%)$ & $19(35.2 \%)$ & 0.568 \\
\hline $2(3.5 \%)$ & $2(3.7 \%)$ & 1.00 \\
\hline $0(0 \%)$ & $0(0 \%)$ & \\
\hline $0(0 \%)$ & $0(0 \%)$ & N/A \\
\hline $0(0 \%)$ & $7(12.9 \%)$ & 0.055 \\
\hline
\end{tabular}


Abbreviations: IM nail = intermedullary nail; DHS = dynamic hip screw, THA = total hip arthroplasty

Table 3: Discharge destination for patients admitted from the community Discharged destination:

COVID-19 $(N=41)$
Control group $(N=50)$

\begin{tabular}{|c|c|c|c|}
\hline Stepdown care* & $20(48.8 \%)$ & $30(60 \%)$ & 0.397 \\
\hline Home & $8(19.5 \%)$ & $12(24 \%)$ & 0.619 \\
\hline $\begin{array}{l}\text { New admission to nursing } \\
\text { home }\end{array}$ & $4(9.8 \%)$ & $0(0 \%)$ & 0.040 \\
\hline Rehab & $8(19.5 \%)$ & $5(10 \%)$ & 0.241 \\
\hline Hospice & $1(2.4 \%)$ & $1(2 \%)$ & 1.00 \\
\hline Not recorded & $0(0 \%)$ & $2(4 \%)$ & 0.498 \\
\hline
\end{tabular}

Note - table excludes inpatient mortality

*Stepdown care included all Model 2 Hospitals within the region 